\title{
Who's Afraid of the Predicate Theory of Names?
}

\author{
Stefano Predelli
}

According to the Predicate Theory of names (PT), proper names 'are predicates', in the sense of displaying a behavior parallel to that of 'general terms which, together with a copula ... are parsed as predicates in formal semantical theory' (Burge 1973: 428-9). According to a particular version of PT, the Metalinguistic Theory (MT), names should be interpreted as predicates of a particular sort, namely as metalinguistically oriented expressions involving 'the name itself'.

The evidence provided in support of PT and MT, having to do with determinername pairs, morphologically inflected names, or naming constructions, is in turn alleged to entail a descriptivist treatment of names in designative position, such as 'Kennedy' in

(1) Kennedy was shot in Dallas.

Accordingly, PT and MT are customarily presented as novel contributions to one of the fundamental debates in philosophical semantics - in particular, as challenges to theories of names as 'directly referring rigid designators' (Matushansky 2008: 573-4).

The main aim of this essay is that of questioning the significance of PT and MT as theories of designation: even granting for the argument's sake that names are analyzable as (metalinguistic) predicates, their designative occurrences may be interpreted in consonance with the dictates of Direct Reference-indeed, in consonance with the radically anti-descriptivist version of Direct Reference I call Millianism. Accordingly, after a few preliminary remarks in section one, in section two I propose an analysis of (1) consistent with PT and MT, but also committed to the notion that (1) is associated with a singular proposition, as Direct Reference demands. In section three, I flank this proposal with an analysis that achieves that singular proposition by appealing to a constant character for 'Kennedy', as required by Millianism.

For simplicity's sake, sections two and three explicitly leave issues of homonymy on the side. Since these issues are of some relevance for my topic, I proceed to a discussion of homonymy in section four, where I contrast an ambiguity approach with what I call 'context-sensitivity' treatments. I conclude this essay in 
section five, where I develop the suggestions from sections two and three with homonymy in the spotlight, and where I amend my Direct Reference and (especially) Millian takes on PT/MT accordingly.

\section{PT and MT: Preliminaries}

Consider the occurrence of 'Kennedy' in

(2) there is a Kennedy in the house

the Kennedy I know speaks French

at least two Kennedys have been Catholic. ${ }^{1}$

According to PT, (2) is evidence that 'Kennedy' is syntactically predicative, on a par with, say, '(is a) cat' (compare with 'there is a cat in the house', 'the cat I know speaks French', and 'at least two cats have been Catholic'). ${ }^{2}$ Writing 'kennedy' as a graphically perspicuous rendering of the predicate in question, the sentences in (2) are then analyzable as

(2a) there is a kennedy in the house

the kennedy I know speaks French

at least two kennedys have been Catholic.

This parallelism is notoriously far from exceptionless, given that names at least superficially tolerate the absence of a determiner, as in the example cited above and repeated here:

(1) Kennedy was shot in Dallas

(contrast with *'cat was shot in Dallas'). Since 'Kennedy' prima facie occurs predicatively in (2) but not in (1), an account of its seemingly dual behavior is imperative. Uncontroversially, the contrast cannot be dismissed as an accidental lexical ambiguity for 'Kennedy', and must be explainable in terms of systematic mechanisms applicable to names across the board. PT's solution in this respect invokes an unpronounced determiner, as in

(1a) det kennedy was shot in Dallas

for some determiner det yet to be discussed.

When it comes to 'kennedy', the predicate involved in the analysans for (1) and (2), an appeal to uniformity and pre-theoretic intuition typically motivates a popular development of PT, the Metalinguistic Theory of names (MT). The reasoning leading 
from PT to MT takes as its starting point the information presumably conveyed by (2), roughly paraphraseable as

(2b) there is an individual named 'Kennedy' in the house

the individual named 'Kennedy' whom I know speaks French

at least two individuals named 'Kennedy' have been Catholic. ${ }^{3}$

On the basis of this evidence, 'kennedy', the predicate allegedly corresponding to the occurrences of 'Kennedy' in (2), is interpreted along metalinguistic lines, as in '(individual) named 'Kennedy'. As a result, by uniformity, (1) is analyzed as

(1b) det named 'Kennedy' was shot in Dallas,

where a metalinguistically oriented predicate is flanked by the aforementioned unvoiced determiner det. $^{4}$

Intuitively, (1) has to do with a particular individual, at least partly in virtue of the occurrence of a name in that sentence - in some vague sense of 'having to do' yet to be clarified, and postponing until section four the discussion of scenarios in which many individuals 'share the same name'. Striving for a neutral terminology, I describe the relationships between that individual and the occurrence of 'Kennedy' in (1) in terms of designation. As long as (1a) and (1b) are assumed to provide a semantically perspicuous analysis of (1), it follows that PT and MT entail a certain explanation of the designation-relation - one which appeals to the semantic properties of the determiner-phrases 'det kennedy' and 'det named 'Kennedy' occurring in the analysans.

The aim of the next two sections is that of exploring PT's and MT's commitments as theories of designation. For the sake of concision, I develop my considerations with an explicit focus on MT, but my conclusions are applicable mutatis mutandis to alternative versions of PT.

\section{MT and Direct Reference}

What then are the characteristic tenets of the theory of designation stemming from MT? MT partisans typically gesture towards descriptivist viewpoints as congenial to their approach, and they cite positions from the Direct Reference camp as their polemical targets. Given the popularity of anti-descriptivist theories of designation committed to Direct Reference, conclusions of this sort would indeed make MT a 
surprising addition to a long-standing debate in philosophical semantics. ${ }^{5}$

Direct Reference appeals to the theoretical framework of propositional semantics, according to which a sentence $S$ is associated (at a context $c$ ) with a structured proposition, in turn representable (given appropriate conventions) as an $n$ tuple containing the contents (at $c$ ) appropriate for the components of $S$. For instance, given a simple sentence $S$ of the form $F a$, the proposition associated with $S$ at $c$ is representable as the pair

$$
<\{a\}_{\mathrm{c}},\{F\}_{\mathrm{c}}>
$$

where, as usual, $\{e\}$ is the character of $e$ (a function from contexts to contents), and $\{e\}_{\mathrm{c}}$ is its content at $c .^{6}$

According to the Direct Reference view of names, (1) is associated with a singular proposition: the propositional constituent for which 'Kennedy' is responsible 'is just the object itself' (Kaplan 1977: 494). As in

$$
<i, \text { shot }>
$$

where $i$ is an individual, and shot is the content of 'was shot in Dallas'-hereinafter, ignoring a variety of tangential complications, simply the property of having been shot in Dallas, in turn understood as a function from circumstances to sets of individuals. ${ }^{7}$ This proposition is evaluated as true with respect to any circumstance $w$ iff $i$ bears shot at $w$, in consonance with the familiar rigid behavior presumably displayed by proper names.

According to MT, (1) is analyzable as (1b), an expression involving a metalinguistic predicate flanked by det. If MT is at all of relevance for the debate on the semantics of proper names, it must be the case that the proposition associated with (1) (at $c$ ) is roughly of the form

$$
<\{\text { det named 'Kennedy' }\}_{\mathrm{c}} \text {, shot }>
$$

where $\{\text { det named 'Kennedy' }\}_{c}$ is the content (at $c$ ) of the determiner-phrase invoked by MT, and shot is as before. The question of the relationships between MT and Direct Reference may thus be settled by addressing the extent to which an approach to det is available, which recognizes (5) as a singular proposition of the kind depicted in (4). ${ }^{8}$

Clearly, those of an independent descriptivist persuasion may wish to pursue strategies responsible for outcomes of general (non-singular) propositions, opting for instance in favor of a treatment of det on the model of (certain views of) attributive uses of the English determiner 'the'. Still, none of the evidence allegedly supporting 
MT prevents an approach in the spirit of Direct Reference. In particular, let det be interpreted as $\operatorname{det}_{s}$ ('s' mnemonic for 'singular'), defined as follows: for any predicate $F$,

(Det $) \quad\left\{\operatorname{det}_{s} F\right\}_{\mathrm{c}}=$ the unique $i$ such that $i \in\{F\}_{\mathrm{c}}\left(c_{w}\right)$

where $c_{w}$ is the circumstance (possible world) determined by $c .{ }^{9}$

Then (temporarily leaving aside the complications arising from homonymy scenarios, see sections four and five), the content of 'det $t_{s}$ named 'Kennedy" at $c$ is the individual $i$ who bears the property \{named 'Kennedy' $\}_{\mathrm{c}}$ at $c_{w}$, that is, the individual $i$ who is named 'Kennedy' at $c_{w} .{ }^{10}$ As a result, (1) ends up being associated (at $c$ ) with a singular proposition as in (4), with $i$ the aforementioned individual. This singular proposition is, as usual, true at a circumstance $w$ iff $i$ bears shot at $w$, that is, iff the individual named 'Kennedy' at $c_{w}$ was shot in Dallas at $w$, consistently with the sort of de jure rigidity outcomes ensuing from Direct Reference. ${ }^{11}$

Of course, whether Direct Reference is at all an unassailable requirement, and, as a consequence, whether (Det $)$ is an independently motivated development of MT, remain issues that need to be addressed in their own right. ${ }^{12}$ But this diatribe is orthogonal to the predicative theory of names: if names in designative positions do indeed engender general propositions (and, perhaps as a result, behave flaccidly), so much the worse for any theory committed to Direct Reference (and/or rigidity), independently of the evidence provided by their presumed predicative occurrences. As I argue in the next section, a parallel strategy is available for a radically antidescriptivist take on names, the version of the singular-proposition approach I call Millianism.

\section{MT and Millianism}

According to the Direct Reference twist on MT in (Det $)$, the occurrence of 'Kennedy' in (1) contributes an individual $i$ at exactly those contexts $c$ such that $i$ is named 'Kennedy' at $c_{w}$. In this sense, 'Kennedy' in (1) (analyzed as 'det $t_{s}$ named 'Kennedy') is associated with a character $f$ such that, for any $c, f(c)$ is the individual named 'Kennedy' at $c_{w}$.

Given certain obvious assumptions regarding who is named what, it follows that, according to $\left(\right.$ Det $\left._{\mathrm{s}}\right)$, the occurrence of 'Kennedy' in (1) is associated with a non- 
constant character: given different contexts, it designates different individuals, depending on who is named 'Kennedy' at their circumstances. ${ }^{13}$ For this reason, $\left(\right.$ Det $_{\mathrm{s}}$ ) remains incompatible with Millianism, the view (at least in my sense of 'Millianism') according to which 'Kennedy' in (1) is endowed with a constant character - the function that determines a particular individual as its content at any $c$. Could it then be that, notwithstanding the predicativists' gesticulations against all versions of Direct Reference, it is in fact Millianism that provides the true polemical target for MT? Here as before, the answer must be negative, as long as the predicative approach furthered by MT may be rendered compatible with the Millian theory of names.

Informally speaking, a determiner-phrase ' $\operatorname{det} F$ ' may be endowed with a constant character only as long as the interpretation of $F$ is prevented from identifying different individuals at distinct contexts. A particularly promising strategy for securing a result of this sort consists in 'fixing' a selected context as the parameter with respect to which $\{F\}$ determines its content 'once and for all', as in the following interpretation of ' $\mathrm{det}^{\prime}$ ' as ' $\operatorname{det}_{m}$ ' ('m' mnemonic for 'Millian'): for any predicate $F$ and context $k$,

(Det D $_{\mathrm{m}}\left\{\operatorname{det}_{m} F, k\right\}=$ the function $f$ such that, for any $c, f(c)=$ the unique $i$ such that $i$ $\in\{F\}_{k}\left(k_{w}\right)$

where as usual $k_{w}$ is the circumstance determined by $k$. In plainer English: given $a$ context $k$, a determiner-phrase $\operatorname{det}_{m} F$ is associated with a constant character, the function which, for any context $c$ as its argument, yields the unique individual in the extension of $F$ at $k$ 's circumstances (as before, continuing to postpone issues of homonymy). In the case of the determiner-phrase of interest here: with respect to $k$, ' $\operatorname{det}_{m}$ named 'Kennedy' is associated with the constant character inevitably yielding whoever happens to be named 'Kennedy' at $k_{w}$. As a result, the MT analysans of (1), now

(6) $\operatorname{det}_{m}$ named 'Kennedy' was shot in Dallas,

is again associated (at $c$ ) with the singular proposition $<i$, shot $>$ (see (4) in section two), where $i$ is the individual named 'Kennedy' at $k_{w}$. And, as before, this proposition turns out to be true with respect to any circumstance $w$ as long as $i$ was shot in Dallas at $w$. The resulting analysis thus achieves rigidity, singularity, and nonindexicality: just as rabidly anti-descriptivist Millians demand. ${ }^{14}$ 
Of course, $\left(\right.$ Det $\left._{\mathrm{m}}\right)$ achieves Millian results on the assumption of a fundamental modification of the classic semantic apparatus I have adopted thus far. In particular, $\left(\right.$ Det $\left._{\mathrm{m}}\right)$ appeals to a double-context treatment, according to which what is endowed with a character is not a lone expression $e$, as in customary double-index treatments, but an expression-context pair $\langle e, k>$. As a result, in the framework invoked by $\left(\right.$ Det $\left._{\mathrm{m}}\right)$, the content for an expression $e$ at a context $c$ may be established only with respect to a further particular context $k$, as in $\{e, k\}_{c}$. For ease of exposition, I refer to the context in the position of $k$ as a dubbing context and I label contexts in the role of $c$ as interpreting contexts. As in: given a dubbing context $k$, the content of $e$ at an interpreting context $c$ is the value of the character $\{e, k\}$ with $c$ as its argument.

Admittedly, given the non-orthodox approach sketched above, the Millian outcomes achieved by (Det $)$ may initially appear to depend on the ad hoc assumption of a mere formal trickery, deprived of independent philosophical interest and intuitive motivation. This suspicion is however unjustified: as I explain in section five, the double context apparatus operative in $\left(\operatorname{Det}_{\mathrm{m}}\right)$, and the associated distinction between dubbing and interpreting roles for context, provide natural developments of certain general (as some would put it, 'metasemantic') considerations that often accompany the Millian semantics for names. Still, the impetus for these considerations derives mainly from issues pertaining to so-called generic names - as in the pre-theoretic notion that, say, John Fitzgerald and Robert bear 'one and the same (last) name', 'Kennedy'. It is thus imperative that I come to grips with the phenomenon of homonymy, thus far explicitly left aside in order to simplify the initial steps of my presentation. Accordingly, after some comments on the relationships between homonymy and MT in the next section, in section five I return to (Det $)$ and especially $\left(\operatorname{Det}_{\mathrm{m}}\right)$, this time with the possibility of homonymy firmly in the spotlight. ${ }^{15}$

\section{His Name is My Name Too}

Consider the contrast between (1) and its negation, that is, between the following two sentences:

(6) Kennedy was shot in Dallas

Kennedy was not shot in Dallas.

Clearly, utterances of these sentences can both be true if, to put it in the vernacular, 
the former is 'about' John Fitzgerald, but the latter is 'about' his brother Robert.

Both classic referentialism and any version of the predicate theory of names owe an explanation of this predicament. A simple strategy popular among referentialists involves an appeal to ambiguity, roughly on the model provided by true utterances of 'Jones went to the bank' and 'Jones did not go to the bank' aimed at describing Jones' movements towards financial institutions and embankments. According to this approach, then, the aforementioned utterances require distinct 'disambiguations' of superficially indistinguishable occurrences of 'Kennedy', roughly as in

Kennedy $_{1}$ was shot in Dallas

Kennedy $_{2}$ was not shot in Dallas, in turn accompanied by appropriate interpretations of the newly introduced artificial lexical items.

No obvious development of this ambiguity approach to homonymy seems to be consonant with MT. According to MT, the constructs in (7) would have to be analyzed along the lines of, respectively,

(det named 'Kennedy'), was shot in Dallas

(det named 'Kennedy') ${ }_{2}$ was not shot in Dallas.

Furthermore, since the dual semantic behavior of these determiner-phrases cannot plausibly be attributed to an ambiguity in det, appropriate disambiguation strategies would have to be mobilized for the predicate, as in

(9) $\quad \operatorname{det}$ (named 'Kennedy') 1 was shot in Dallas

$\operatorname{det}$ (named 'Kennedy') $)_{2}$ was not shot in Dallas.

Yet, a result of this kind would prove problematic when it comes to the evidence that provides the very impetus for predicativism, having to do with cases such as (2). For, according to the ambiguity view, the religious alliances of John Fitzgerald and Robert would no more justify the conclusion that, say,

(10) at least two Kennedys were Catholic

than the presence in my room of a hitting device and a certain flying mammal could provide the conditions for a true utterance of 'there are two bats in my room'. ${ }^{16}$

Indeed, according to MT, cases such as (10) are analyzed as

(11) at least two individuals named 'Kennedy' were Catholic,

and are thus actually true only if more than one individual may satisfy the condition of being named 'Kennedy' at our world. In this sense, the property provided by 'named $n$ ' (at $c$ ) must be understood in such a way that distinct individuals $i$ and $j$ may 
both belong in the extension it determines with respect to a given circumstance. If, by uniformity, a property of this sort is of relevance for the determiner-phrases involved in the analysis of the sentences in (6), it follows that utterances of these sentences may be interpreted correctly only if suitably different restrictions are imposed on the named- 'Kennedy' condition - pre-theoretically speaking, restrictions that secure John Fitzgerald in one case, and Robert in the other. In semantic terms, this idea corresponds to the notion that the determiner-phrases occurring in the MT analyses of (6) must be evaluated with respect to distinct parameters. A natural option in this respect, one of particular interests due to its repercussions when it comes to $\left(\operatorname{Det}_{\mathrm{s}}\right)$ and $\left(\right.$ Det $\left._{\mathrm{m}}\right)$, identifies the parameters in question as elements of context—say, as dedicated co-ordinates $c_{n}$, informally $c$ 's 'naming convention'.

The idea of a 'naming convention' notoriously deserves independent study. ${ }^{17}$ Still, from this essay's viewpoint, the details pertaining to the sort of linguistic and extra-linguistic regularities eventually formalizable in terms of $c_{n}$ may safely be left aside. For concreteness' sake, I proceed without further ado with an understanding of $c_{n}$ as a 'disambiguating' restriction — say, a function such that, for any name $n$ and circumstance $w, \mid c_{n}$ (named $\left.n(w)\right) \mid=1$, where named $n(w)$ is the set of individuals who are named $n$ at $w .{ }^{18}$ So, informally, John Fitzgerald is the unique actual individual who is named 'Kennedy' according to a certain naming convention $f_{1}$, and Robert is the unique actual individual who is named 'Kennedy' according to a distinct naming convention $f_{2}$.

According to this context-sensitive alternative to the ambiguity view, then, the aforementioned utterances of the sentences in (6) are understood as occurrences of one and the same expression on different occasions - in particular, on occasions representable by contexts which differ with respect to their naming-convention parameters. I devote the next section to the exploration of how this sort of contextsensitivity may be reflected at the level of semantic analysis, with particular attention to its relationships with the treatments of det introduced in sections two and three. In particular, after a few comments on the indexicalist take that naturally accompanies $\left(\right.$ Det $\left._{\mathrm{s}}\right)$, I pause on an account of context-sensitivity consonant with the double-context paradigm developed for $\left(\operatorname{Det}_{\mathrm{m}}\right)$, indirectly making good on my pledge to explain its independent philosophical motivation. 


\section{Homonymy, Direct Reference, and Millianism}

Given the standard semantic treatment adopted in section two (as opposed to the unorthodox double-context framework from section three), the notion that certain expressions are context-sensitive is immediately translatable in terms of non-constant characters. In this framework, then, the determiner-phrase which MT associates with the occurrence of 'Kennedy' in (1) may designate different individuals at different contexts - in particular, at contexts that differ for their naming-convention. ${ }^{19}$

Here as in section two, this option may be developed along straightforwardly descriptivist lines, but may also be approached from a viewpoint sympathetic to Direct Reference, as in the following development of (Det $)$ :

$\left(\right.$ Det* $\left._{\mathrm{s}}\right) \quad\left\{\operatorname{det}_{s} F\right\}_{\mathrm{c}}=$ the unique $i$ such that $i \in\left(c_{n}\right)\left(\{F\}_{\mathrm{c}}\left(c_{w}\right)\right)$

So, given a context $c,\left\{\operatorname{det}_{\mathrm{s}} \text { named 'Kennedy' }\right\}_{\mathrm{c}}$ is the unique individual selected by $c_{n}$ among those who are named 'Kennedy' at $c_{w}$. Note that, according to (Det*s), det $_{\mathrm{s}}$ phrases are endowed with a non-constant character 'over and above' the sense appropriate for $\left(\right.$ Det $\left._{\mathrm{s}}\right)$. Clause $\left(\right.$ Det $\left._{\mathrm{s}}\right)$, developed under the temporary assumption of lack of homonymies, recognizes semantic variations only when it comes to contexts $c$ that differ with respect to their privileged circumstances $c_{w}$. (Det* ${ }^{*}$ ), on the other hand, also allows for a distinction among individuals who bear a certain name at one unique circumstance, depending on the details in $c_{n}$.

Since Millianism is incompatible with the assignment of non-constant characters to proper names, a Millian understanding of the context-sensitivity approach to homonymy inevitably needs to limit the role of $c_{n}$ to the sort of effects achieved by 'dubbing contexts' within the double-context apparatus from section three. As in:

$\left(\right.$ Det $\left._{\mathrm{m}}{ }_{\mathrm{m}}\right) \quad\left\{\operatorname{det}_{m} F, k\right\}=$ the function $f$ such that, for any $c, f(c)=$ the unique $i$ such that $i \in\left(k_{n}\right)\left(\{F\}_{\mathrm{k}}\left(k_{w}\right)\right)$.

So, given a dubbing context $k$, (Det ${ }^{*}$ ) sanctions that the character for ' $\operatorname{det}_{m}$ named 'Kennedy', when applied to an interpreting context $c$, yields a certain unique individual, the individual selected by $k$ 's naming convention among those who are named 'Kennedy' at $k_{w}$.

It is at this stage that the two-context apparatus I invoked in section three may hopefully be understood as more than philosophically unmotivated formal hocuspocus. Recall to begin with the sort of warning common in informal discussions of 
designation, variously phrased as the intimation that designating is not the business of a name simpliciter, but rather of a use of that name on a certain occasion, an occurrence of it in a particular speaker's mouth, or something of that sort. According to a viewpoint often associated with the Direct Reference movement, these allusions to 'uses' or 'occurrences' may profitably be modulated in the spirit of the so-called Causal (a.k.a. Historical) Picture of names: an utterance of 'Kennedy' on a particular occasion designates John Fitzgerald, rather than Robert or anybody else, by virtue of bearing a suitable relation to a dubbing episode involving that man-on a particularly simple version of the Causal Picture, by virtue of occurring as a link within a designation-preserving chain originating with his baptism. ${ }^{20}$

At least from the viewpoint of the theory of designation, it is natural to develop these hints in terms of a certain conception of the proper input for semantic evaluation: not generic name-types, such as the seven-letter expression 'Kennedy', but items of a more fine-grained nature, such as an occurrence of 'Kennedy' as a name for John Fitzgerald. ${ }^{21}$ Since the normal process of everyday communication ostensibly involves tokens of 'Kennedy', the name-type, these suggestions typically end up promoting some sort of division of labor between properly semantic and socalled pre-semantic considerations. As in (roughly): given your position within a network of name-transmission practices originating with $i$, the occurrence of 'Kennedy' in your mouth is interpretable in consonance with the properties associated by an adequate semantic theory with expressions devoted to designating $i$, rather than anybody else. ${ }^{22}$

The picture sketched in the foregoing paragraphs is admittedly rough and in dire need of development. Still, the point here is not the discussion of the relationships between pre-semantic and properly semantic questions, given viewpoints suitable for a theory of designation. After all, if the predicativist evidence summarized in section one is on the right track, designation does not exhaust a name's genuinely semantic behavior: proper names, so the story goes, are also employable in non-designative roles, as in (2). Since these example are presumably worthy of semantic consideration, it follows that the faith of generic name-types, such as the common appellation for John Fitzgerald and Robert, may not be relegated to the pre-semantic limbo. As a result, it follows that the distinction between 'Kennedy' as a name for John Fitzgerald and 'Kennedy' as a name for Robert must be the responsibility of some parameter 'internal' to the semantic machinery put in motion for their 
interpretation.

Given the Millian notion that proper names are endowed with a constant character, the idea of a semantic parameter responsible for the distinction between different uses of 'Kennedy' must inevitably end up with the recognition that context plays a role over and above (figuratively, 'before') its ability to serve as argument for character-indeed, a role responsible for the assignment of a character to a nametype, as it is being used on a particular occasion. What a Millian theory concerned solely with the details of the designation relation could afford to relegate to presemantic context is thus now naturally recognized as a distinct semantic function for context, one naturally formalizable in terms of the distinction between dubbing contexts and interpreting contexts, as suggested in section three. ${ }^{23}$

\section{Conclusion}

The main aim of this essay has been that of arguing that PT and MT do not provide momentous evidence in favor of this or that theory of designation-even under the assumption of PT/MT's (possibly controversial) appeals to intuition and uniformity. In sections two and three, I defended this conclusion by suggesting developments of PT and MT consistent with eminently non-descriptivist viewpoints, such as Direct Reference and Millianism. Sections four and five pursued these approaches not only from the viewpoint of a theory of designation, but also from perspectives directly interested in generic names, as in cases of homonymy. The resulting semantic standpoints indirectly explain how non-designative occurrences of proper names, such as 'Kennedy' in (2), may be explained without relinquishing anti-descriptivist

explanations of designation. In particular, the (presumed) evidence favoring an account of names 'as predicates' may peacefully co-exist with Direct Reference and Millian accounts of det, the determiner allegedly at work in designative occurrences, as in $\left(\right.$ Det* $\left._{\mathrm{s}}\right)$ and $\left(\right.$ Det* $\left._{\mathrm{m}}\right)$ from section five.

Department of Philosophy, University of Nottingham

stefano.predelli@nottingham.ac.uk 


\section{References}

Bach, Kent 1981. What's in a Name. Australasian Journal of Philosophy 59:371-386.

Bach, Kent 1987. Thought and Reference. Oxford University Press.

Bach, Kent 2002. Giorgione Was So-Called Because of His Name. Philosophical Perspectives 16: 73-103.

Boer, Steven E. 1975. Proper Names as Predicates. Philosophical Studies 27: 389400.

Borg, Emma 2000. Complex Demonstratives. Philosophical Studies 97: 229-249.

Burge, Tyler 1973. Reference and Proper Names. The Journal of Philosophy 70: 425439.

Devitt, Michael 1981. Designation. Columbia University Press.

Evans, Gareth 1973. The Causal Theory of Names. Proceedings of the Aristotelian Society, Supp. Vol. 47: 187-208.

Fara, Delia Graff 2011. You Can Call Me 'Stupid', ... Just Don't Call Me Stupid. Analysis 71.3: 492-501.

Frege, Gottlob 1892. On Sense and Reference. In P. Geach and M. Black (eds.), Translations from the Philosophical Writings of Gottlob Frege. Blackwell $1952,56-78$.

Geurts, Bart 1997. Good News About the Description Theory of Names. Journal of Semantics 14: 319-348.

Glüer, Kathrin, and Peter Pagin 2006. Proper Names and Relational Modality. Linguistics and Philosophy 29: 507-535.

Jeshion, Robin 2013a. Names Not Predicates. In Andrea Bianchi (ed.), On Reference. OUP.

Jeshion, Robin 2013b. A Rejoinder to Fara's 'Literal Uses of Proper Names'. In Andrea Bianchi (ed.), On Reference. OUP.

Jeshion, Robin 2013c. Proper Names, Proper Nouns. Erkenntnis.

Kaplan, David 1977. Demonstratives. In J. Almog, J. Perry, and H. Wettstein (eds.), Themes from Kaplan. Oxford University Press, 481-563.

Kaplan, David 1989. Afterthoughts. In J. Almog, J. Perry, and H. Wettstein (eds.), Themes from Kaplan. Oxford University Press.

Kaplan, David 1990. Words. Proceedings of the Aristotelian Society, Supp. Vol. 64: 93-119. 
Katz, Jerrold J. 1977. A Proper Theory of Names. Philosophical Studies 31: 1-80.

Katz, Jerrold J. 1990. Has the Description Theory of Names Been Refuted? In G. Boolos (ed.), Meaning and Method: Essays in Honor of Hilary Putnam. Cambridge University Press.

Katz, Jerrold J. 1994. Names Without Bearers. The Philosophical Review 103: 1-39.

King, Jeffrey 2007. The Nature and Structure of Content. OUP.

Kneale, William 1962. Modality de dicto and de re. In E. Nagel, P. Suppes, \& A. Tarski (eds.), Logic, Methodology and Philosophy of Science. Stanford University Press, 622-633.

Kripke, Saul 1980. Naming and Necessity. Harvard University Press.

Leckie, Gail 2013. The Double Life of Names. Philosophical Studies 165: 1139-1160.

Lewis, David 1980. Index, Context, and Content. In S. Kanger and S. Öhman (eds.), Philosophy and Grammar. Reidel.

Matushansky, Ora 2008. On the Linguistic Complexity of Proper Names. Linguistics and Philosophy 21: 573-627.

Pelczar, M., and J. Rainsbury 1998. The Indexical Character of Names. Synthese 114: 293-317.

Perry, John 2001. Reference and Reflexivity. CSLI.

Predelli, Stefano 2005. Contexts: Meaning, Truth, and the Use of Language. Oxford University Press.

Rami, Dolf 2013. On the Unification Argument for the Predicate View of Proper Names. Synthese

Recanati, Francois 1997. Direct Reference: From Language to Thought. Blackwell.

Russell, B. (1911). Knowledge by Acquaintance and by Description. In B. Russell (ed.), Mysticism and Logic and Other Essays. Longmans, Green, and Co., 209-232.

Salmon, Nathan 2002. Demonstrating and Necessity. The Philosophical Review 111: 497-537.

Salmon, Nathan 1986. Frege's Puzzle. MIT Press.

Searle, John R. 1958. Proper Names. Mind 67: 166-173.

Soames, Scott 1987. Direct Reference, Propositional Attitudes and Semantic Content. Philosophical Topics 15: 47-87.

Voltolini, Alberto 1995. "Indexinames”. In J. Hill and P. Kotàtko (eds.), Karlovy Vary Studies in Reference and Meaning. Philosophia Publications, 258-285. 
${ }^{1}$ As for the inflection in the last sentence in (2), note that the analogy between names and common nouns is far from perfect. For one thing, the preferred plural for 'Kennedy' is 'Kennedys', not 'Kennedies'. For another, the plural form is arguably optional: both 'there are two Marys in my class' and 'there are two Mary in my class' are acceptable, but 'there are two cat in my class' is not.

${ }^{2}$ Further considerations in favour of PT stem from the syntax of naming constructions, as in Matushansky's analysis in terms of small clauses (Matushansky 2008; for different considerations regarding naming constructions, see also Fara 2011).

${ }^{3}$ The inevitability of metalinguistic paraphrases has been challenged by Boer and Jeshion (Boer 1975, Jeshion 2013a, 2013b, and 2013c), who present an impressive variety of examples arguably parallel to (2), but which do not elicit metalinguistic interpretations.

${ }^{4}$ For careful critical discussions of this appeal to uniformity see in particular Jeshion 2013a and 2013b, Leckie 2013, and Rami 2013. As announced, I leave these worries aside (and those of the sort mentioned in the preceding footnote) merely for the argument's sake.

Many details in (1b) are worthy of independent study. Defenders of MT devote a great deal of attention to the relation mentioned in (1b), occasionally distinguishing between 'being named', 'bearing a name', and 'being called' (see Matushansky 2008, Fara 2011 and, from neighbouring metalinguistic descriptivist camps, Bach 2002 and Geurts 1997). To my knowledge, remarkably less effort is devoted to the study of that relation's second relatum, the quotational expression. Yet, none of these complications are of immediate importance here, my considerations being rephraseable according to any reasonable understanding of 'being named' and of mentioning devices.

${ }^{5}$ The most explicit statements in this respect come from Matushansky, according to whom PT/MT supports a descriptivist stance, in some wide sense of descriptivism supposed to include Frege 1892, Russell 1911, Searle 1958, Kneale 1962, Burge 1973, Katz 1977, 1990, 1994, and Bach 1981, 1987, 2002 (Matushansky 2008: 5734).

${ }^{6}$ The notation and terminology are borrowed from Kaplan 1977. For developments, see Salmon 1986 and Soames 1987; for general philosophical comments, see also King 2007.

${ }^{7}$ In the sense of 'circumstance' from Kaplan 1977, hereinafter for simplicity's sake merely possible worlds. So, leaving aside issues of tense and pretty much any other detail ensuing from the internal composition of this verb-phrase, \{was shot in Dallas $\}_{c}$ $(w)$ is the set of individuals who bear shot at $w$.

${ }^{8}$ The (simplified) propositional structure presented in (5) is obviously inspired by the classic treatment informally put forth by Kaplan (Kaplan 1977 and 1989). Strictly speaking, some independently important details in this respect are however in contrast with the spirit of Kaplan's own version of propositional semantics - in particular when it comes to the treatment of what he would presumably consider a 'syntactically complex' expression such as 'det named 'Kennedy' (see in particular Kaplan 1977: 494 and especially the discussion of 'dthat' in Kaplan 1989: 580-2 and the related distinction between 'logical syntax' and 'semantic form'). Still, considerations of this 
sort may safely be left aside when it comes to the diatribe addressed in this essay.

${ }^{9}$ See Kaplan 1977 and Lewis 1980. Throughout this essay, I leave aside questions of 'emptiness', thereby eschewing 'if any' caveats; as for uniqueness, see the considerations later in this essay.

${ }^{10}$ If the present tense in '(is an individual) named 'Kennedy"' is treated according to a simple-minded indexical model, \{named 'Kennedy' $\}_{c}$ is the property of being named 'Kennedy' at $c_{t}$, the context's time, so that \{named 'Kennedy' $\}_{c}\left(c_{w}\right)$ is the set of individuals who are named 'Kennedy' at $c_{t}$ and $c_{w}$. Issues of tense and temporal dependence are ignored throughout this essay - the point of this footnote being rather than of stressing the two-fold role of $c$ in the identification of $\{F\}_{c}\left(c_{w}\right)$, first as a parameter for the interpretation of indexicality, then as a co-ordinate relevant from the viewpoint of contingency (see Kaplan 1977 and Lewis 1980).

${ }^{11}$ The strategy in $\left(\right.$ Det $\left._{\mathrm{s}}\right)$ is reminiscent of Kaplan conception of 'dthat' as a device of direct reference, see Kaplan 1977 and 1989. These similarities are particularly intriguing if approached from the viewpoint of certain Kaplan-inspired views of complex demonstratives, according to which the material flanking 'that' compositionally determines the character of 'that $F$ ' (see Borg 2000 and Salmon 2002). A suggestion of this sort inevitably brings to mind what is generally cited as the original source of the predicative stance on proper names, Tyler Burge's 'Reference and Proper Names' (Burge 1973). According to Burge, the determiner involved in the analysis of designative occurrences of proper names is a demonstrative 'that', as in 'that individual named 'Kennedy'. Noteworthy in this respect is the fact that Burge not only refrains from any attack against the Direct Reference movement, but in fact explicitly endorses at least some of its distinctive tenets (Grice's 'Vacuous Names', as far as I can tell, is the only source Burge indicates as incompatible with his approach to names; see Burge 1973: 428 fn. 4 and 434 fn. 13; 426 footnote 3 ).

${ }^{12}$ In particular, at least some descriptivist sources sympathetically mentioned by PT partisans take issue with Kripke-style arguments for rigidity, and propose ingenious examples apparently motivating a flaccid approach to proper names (Bach 2002, Geurts 1997). Uncontroversially, these examples need to be assessed in their own right, with no significant repercussions for the semantic implications of PT and MT.

${ }^{13}$ This is so, of course, even continuing to disregard the possibly indexical features introduced by tense in '(is an individual) named 'Kennedy'.

${ }^{14}$ A referee for this journal calls my attention to some points of contact between this strategy and the idea of a 'switcher' in Glüer and Pagin 2006. The analogies are intriguing, possibly modulo certain delicate issues having to do with the comparison of different semantic frameworks (Glüer and Pagin 2006 puts forth a model-theoretic approach grounded on the idea of an 'actualist evaluation' for individual constants, in turn applicable to the interpretation of occurrences of proper names within the scope of certain operators).

${ }^{15}$ The reiteration of a methodological caveat implicit in these considerations may be appropriate at this stage: if what follows is on the right track, my two-context proposal may be approached as a relatively natural formalization of certain prima facie plausible ideas. As a referee for this journal correctly points out, this much is not equivalent to the guarantee that my framework will be unproblematically generalizable and adaptable to larger fragments. This worry is legitimate, but puts a relatively heavy burden on my opponent's shoulders: that of identifying inconsistent or otherwise intolerable consequences of what appears as a relatively minimal, though 
admittedly non-trivial deviation from standard double-index approaches.

${ }^{16}$ Or, for that matter, 'no less': see in particular the discussion in Jeshion 2013c (including a 'bat' example attributed to Karen Lewis) and in Leckie 2013. Jeshion's and Leckie's examples weaken the case for MT, and indicate that the phenomena allegedly supporting MT are in fact derivable from regularities independent of the semantics of proper name. I leave these important considerations aside merely for methodological purposes, given the aim stated at the beginning of this essay: the discussion of the semantic consequences of PT and MT, granting (merely for the sake of argument) that these views are indeed properly motivated.

${ }^{17}$ I suppose the so-called 'metasemantic' theses often subsumed under the heading of the Causal (a.k.a. Historical) Theory of names may provide a fertile background for the development of a 'theory of naming conventions'- see among many Evans 1973, Kripke 1980, and Devitt 1981.

${ }^{18}$ As usual, ignoring for simplicity's sake issues of emptiness.

19 The indexicalist take includes views which informally gloss 'det' as a demonstrative, as in Burge 1973, or which include among the elements of context some sort of 'naming convention' (as in Matushansky 2008: 592, citing Recanati 1997 and Pelczar and Rainsbury 1998; for indexicalist views of names, see also Voltolini 1995).

${ }^{20}$ Regarding the Causal/Historical Theory of names and the related ideas of a 'baptism' and a 'dubbing', see for instance Evans 1973, Kripke 1980, Devitt 1981, and Kaplan 1981. The Causal/Historical Theory is occasionally associated with distinctive metaphysical views about the individuation of words, and names in particular, as in Kaplan 1990.

${ }^{21}$ For a related distinction at the level of word-individuation, see Kaplan's divide between 'orthographic' names and 'common currency' names, Kaplan 1990.

${ }^{22}$ For general comments pertaining to the distinction between pre-semantic and semantic roles of context, see in particular Perry 2001 and Predelli 2005.

${ }^{23}$ From a typographical point of view, this idea may be expressed in terms of a reinterpretation of the artificial devices postulated by the ambiguity treatment of homonymy, according to which the occurrence of 'Kennedy' in 'Kennedy' is of greater significance than, say, the occurrence of 'cat' in 'catatonic'. Think, in other words, of the numerical appendix in 'Kennedy,' as a remnant of those elements of (formerly 'pre-semantic') context that do make a difference when it comes to character, as in <'Kennedy', $k_{1}>$ and <'Kennedy', $k_{2}>$, the name/dubbing-context pairs. 